\title{
RENIN ANGIOTENSIN SYSTEM-DEPENDENT AND -INDEPENDENT FUNCTIONS OF (PRO)RENIN RECEPTOR AND THE ROLES OF ITS BLOCKERS
}

\author{
Kazal B. Biswas ${ }^{1 *}$, A.H.M. N. Nabi ${ }^{2}$, Akio Ebihara ${ }^{3}$, Tsutomu Nakagawa ${ }^{3}$, Arunasiri \\ Iddamalgoda $^{1}$, Fumiaki Suzuki ${ }^{3}$
}

${ }^{1}$ Department of Research and Development, Ichimaru Pharcos Co. Ltd., Motosu, Gifu 501-0475, Japan

${ }^{2}$ Department of Biochemistry and Molecular Biology, University of Dhaka, Dhaka-1000, Bangladesh

${ }^{3}$ Faculty of Applied Biological Sciences, Gifu University, 1-1 Yanagido, Gifu 501-1193, Japan

\section{ABSTRACT}

(Pro)renin receptor $[(\mathrm{P}) \mathrm{RR}]$ is one of the major components of the renin angiotensin (RA) system, which is involved in the regulation of blood pressure. $(\mathrm{P}) \mathrm{RR}$ binds with and increases the activity of mature renin, the key regulatory enzyme of RA system, which catalyzes the conversion of angiotensinogen to angiotensin-I. (P)RR also binds to the inactive form of renin called prorenin. Receptor-bound prorenin exerts biochemical and molecular effects in either an angiotensin II-dependent or -independent manner. RA system-independent function and/or involvement of (P)RR has been well reported. Inhibition of binding and activation of renin/ prorenin to $(\mathrm{P}) \mathrm{RR}$ has been found to improve proteinuria in diabetic model rats. This article reviews the action of (P)RR blockers as well as its associated mechanism.

Keywords:Renin, Prorenin, (Pro)renin receptor, Aliskiren, Decoy peptide, Hinge peptide, Handle region peptide,

Renin angiotensin system, Wnt signaling

\section{Introduction}

The discovery of the renin-angiotensin (RA) system was initiated in 1898 when Tigerstedt and Bergman first reported the existence of a pressor substance in renal extracts, which they named "renin" based on its origin (Tigerstedt and Bergman, 1898). Despite its discovery almost 115 years ago, the functioning of the RA system is still an area of active research, owing to its complexity and obscure nature. This system is extensively involved in a diverse range of physiological and pathophysiological functions, such as growth and remodeling, development, inflammation, vascular hypertrophy, and thrombosis (Ito et al., 1995; Siragy and Carey, 1997; Goto et al., 1997; Gross et al., 2000). The classical RA system is a circulating endocrine system regulated by renin, a rate-limiting enzyme secreted in the kidney, which proteolytically cleaves the liver-borne angiotensinogen to form the inactive decapeptide, angiotensin I (Ang I). The angiotensin-converting enzyme (ACE) further removes two $\mathrm{C}$-terminal amino acids in angiotensin I, thereby generating the octapeptide angiotensin II (Ang II). Ang II exerts numerous physiological effects through the actions of angiotensin II type $1\left(\mathrm{AT}_{1}\right)$ and angiotensin II type $2\left(\mathrm{AT}_{2}\right)$ receptors (Ito et al., 1995; Siragy and Carey, 1997; Goto et al., 1997; Gross et al., 2000). Prorenin, an inactive precursor of renin, functions as a marker of diseases like Wilm's tumor (Leckie et al., 1994) and diabetes (Luetscher et al., 1985), due to its extensive presence in plasma. The (pro) renin receptor ((P)RR)-bound, non-proteolytically activated form of prorenin is involved in Ang I generation (Danser and Deinum, 2005; Danser et al., 2008).

A novel aspect of the receptor-associated renin/prorenin system was recognized following the discovery of (P)RR in 2002 by Nguyen (Nguyen et al., 2002). This receptor was shown to bind both renin and prorenin. Upon interaction with (P)RR, the catalytic activity of renin increased by a factor of 5 , while prorenin became fully activated via a conformational change, which resulted in the opening of a prosegment and exposure of the active site (Nguyen and Contrepas, 2008, Suzuki et al., 2003). The locally anchored renin and activated prorenin on the receptor supply angiotensin peptides to the local tissues; furthermore, they also stimulate the transduction of receptor signaling, including that of phospho-p42/ 
Please cite this articles as:

Biswas et al, Reviews in Agricultural Science, 2: 37-47, 2014 doi: $10.7831 /$ ras. 2.37

p44 extracellular signal-regulated kinase (ERK) 1/2 (Nguyen et al., 2002), phospho-p38 mitogen activated protein (MAP) kinase (Saris et al., 2006), profibrotic transforming growth factor (TGF)- $\beta 1$ (Huang et al., 2006; Nguyen and Danser, 2008), inflammatogenic cyclooxygenase-2 (COX-2) (Kaneshiro et al., 2006), and heat shock protein (HSP) 27 in cardiomyocytes (Saris et al., 2006), which are involved in the end-stage organ damage mechanism of kidney, heart, vasculature, retina, etc. Schefe et al. have also demonstrated a novel signal transduction mechanism of (P)RR through promyelocytic zinc finger (PLZF) protein, which down-regulates the expression of the (P)RR itself (Schefe et al., 2006). (P)RR has also been reported to be involved in a RA system-independent pathway, the protooncogene protein Wnt signaling pathway (Nguyen, 2011). In this article, we have reviewed recent data on the involvement of (P)RR in pathways, which are dependent and/or independent of the RA system (Figure 1). We have also discussed reports on the inhibitory and/or regulatory mechanisms of these pathways.

\section{(P)RR, a mysterious player in the RA system}

Currently, there exists overwhelming evidence of the functional versatility of $(\mathrm{P}) \mathrm{RR}$, more than 10 years after its discovery by Nguyen (Nguyen et al., 2002). (P)RR is expressed widely, corresponding to the high expression of its mRNA, in the human brain, heart, and placenta. To a lesser extent, it is also expressed in the liver, pancreas, and kidney, in addition to weak expression in the lung and skeletal muscles (Nguyen et al., 2002). (P)RR is also expressed in the human retina (Demirci et al., 2001). In situ hybridization has indicated the expression of (P)RR mRNA in the glomeruli, tubules, and vessels of rat kidney (Krebs et al., 2007; Ichihara et al., 2006a). Immunocytochemical studies have shown that the distal renal tubule is the main site of $(\mathrm{P}) \mathrm{RR}$ expression in the kidney of rats and humans (Nguyen, 2006). It has also been identified within the mesangial area of the glomeruli (Nguyen et al., 2002), in vascular smooth muscle cells of renal and coronary vessels (Nguyen et al., 2002), neonatal rat cardiomyocytes (Saris et al., 2006), and human monocytes (Feldt et al., 2008).

(P)RR is a 350 -amino acid long protein molecule with a single transmembrane domain (Nguyen et al., 2002). Although it was first identified in cultured human mesangial cells, the C-terminal portion of the receptor was described earlier by Ludwig et al. (1998) as an 8.9-kDa fragment associated with a vacuolar $\mathrm{H}^{+}$-ATPase. It has a large, non-glycosylated, highly hydrophobic amino-terminal domain that is responsible for the binding of renin and prorenin, and a short cytoplasmic tail of approximately 20 amino acids (Burckle and Bader, 2006). The nucleotide and amino acid sequence of (P)RR exhibits no homology with any known protein. Tertiary structure homology has not yet been determined, owing to a lack of knowledge of the (P)RR crystal structure, although the structure of the cytoplasmic domain of (P)RR has already been resolved (Zhang et al., 2011). The (P)RR encoding gene, ATP6ap2, is located on the $\mathrm{X}$ chromosome at locus p11.4. Analysis of the (P)RR sequence revealed that it is identical to multiple proteins, including ATPase, the $\mathrm{H}^{+}$transporting lysosomal

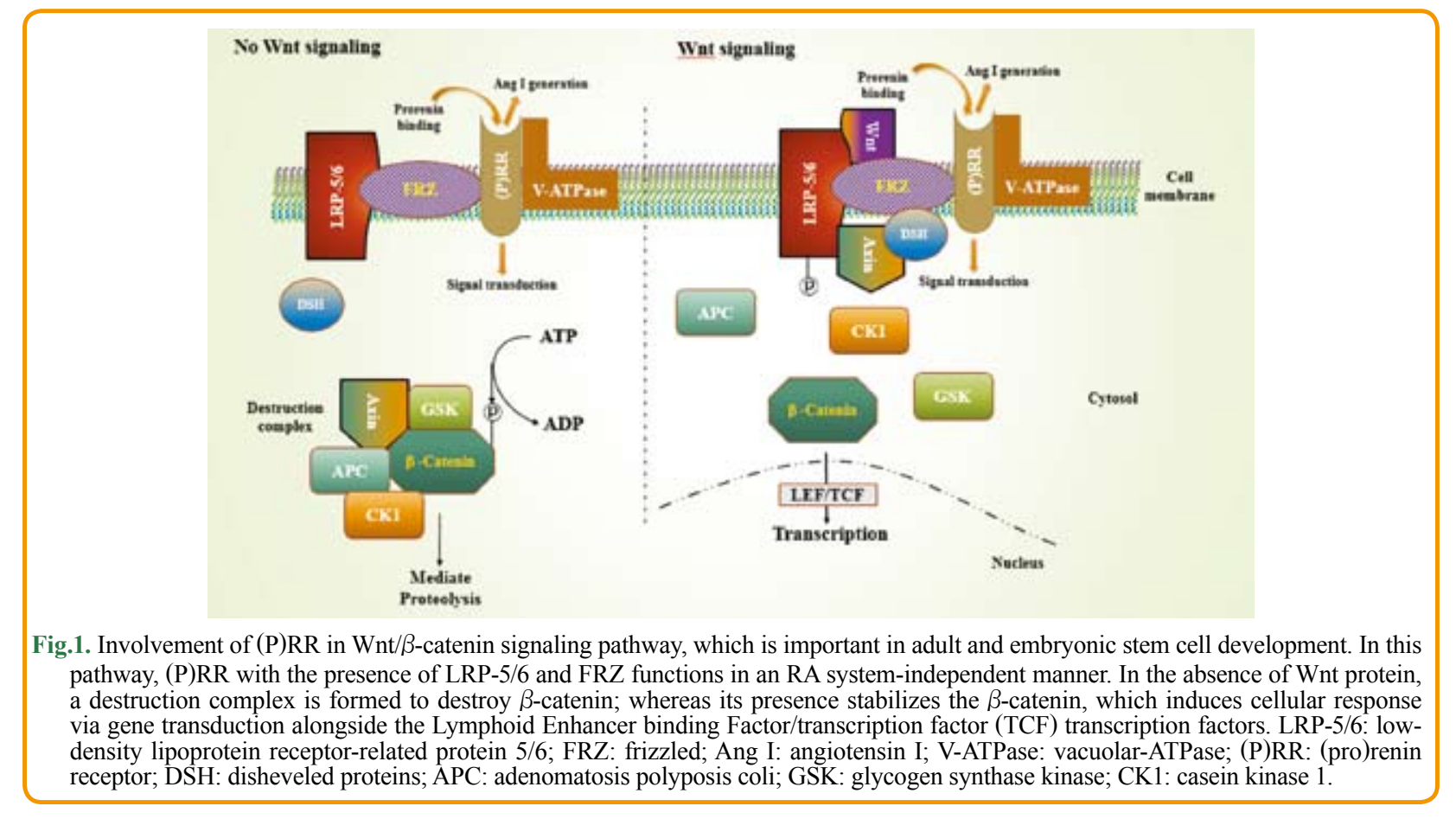


Please cite this articles as:

Biswas et al, Reviews in Agricultural Science, 2: 37-47, 2014.

doi: $10.7831 /$ ras. 2.37

accessory protein 2 (ATP6AP2), and endoplasmic reticulum-localized type I transmembrane adapter precursor (CAPER) (Schefe et al., 2006; Burckle and Bader, 2006; Ramser et al., 2005). ATP6AP2 is associated with vacuolar ATPases (V-ATPase), which is involved in several cellular functions, such as neurotransmitter uptake and storage, endocytosis, and receptor recycling (Nelson and Harvey, 1999). V-ATPase is a complex, 13-subunit protein, essential for the maintenance of an acidic $\mathrm{pH}$ in intracellular vesicles, and for regulation of cellular $\mathrm{pH}$ homeostasis (Nishi and Forgac, 2002).

\section{Binding of renin and prorenin to $(\mathrm{P}) \mathrm{RR}$}

(P)RR was first cloned and sequenced from a human kidney cDNA library. The binding of radiolabeled renin to mesangial cells stably transfected with (P)RR, shows a dissociation constant $\left(K_{\mathrm{D}}\right)$ of 5.0-7.8 nM (Nguyen et al., 2002). Based on the observed molecular weight of the cross-linked renin-receptor complex, Nguyen et al. (2002) proposed that (P)RR exists as a dimer, a theory that has been confirmed by Schefe et al. (2006). Nabi et al. (2006) observed that rat prorenin exhibited a higher binding affinity toward $(\mathrm{P}) \mathrm{RR}$, compared to the rat renin molecule, in in vitro experiments using rat recombinant $(\mathrm{P}) \mathrm{RR}$ expressed in the baculovirus expression system. The $K_{\mathrm{D}}$ values expressed by prorenin and renin in this experiment are 8.0 and $20.0 \mathrm{nM}$, respectively. Nurun et al. (2007) subsequently cloned and expressed rat $(\mathrm{P}) \mathrm{RR}$ in COS-7 (CV-1 origin simian vacuolating virus 40 cell line) cells, and observed the binding of rat prorenin to the receptor with a $K_{\mathrm{D}}$ of $0.89 \mathrm{nM}$. Additionally, it was observed that $90 \%$ of rat prorenin (at an initial concentration of $2.0 \mathrm{nM}$ ) binds to (P)RR, which is overexpressed on the membrane of COS-7 cells (Nurun et al., 2007). Parallel experiments have shown that human prorenin binds to the human (P)RR expressed on the COS-7 cell surface, with a $K_{\mathrm{D}}$ of $1.8 \mathrm{nM}$ (Nurun et al., 2007). Overexpressed human (P)RR can bind to $50 \%$ of human prorenin, when the initial concentration of prorenin is set at $2.0 \mathrm{nM}$ (Nurun et al., 2007). Nabi et al. (2009a and 2009b), used a recombinant human (P)RR expressed in an in vitro cell-free expression system, and confirmed the binding of recombinant human renin and prorenin by surface plasmon resonance in the BIAcore assay system, as well as at equilibrium state. The $K_{\mathrm{D}}$ values for binding of renin and prorenin to the immobilized (P) RR were 4.4 and 1.2 $\mathrm{nM}$ respectively, using the BIAcore system, and 4.5 and $1.0 \mathrm{nM}$ respectively, at equilibrium state (Nabi et al., 2009a and 2009b). Feldt et al. (2008) have observed the binding of radiolabeled human renin and prorenin to human U937 (human macrophage cell line) monocytes. In contrast, Batenburg et al. (2007) have reported the binding of human prorenin, but not of renin, to the human (P)RR expressed on the smooth muscle cells of transgenic rats; the $K_{\mathrm{D}}$ for prorenin binding was $5.9 \mathrm{nM}$. Zhang et al. (2008) also observed the activation of rat prorenin, which is bound to rat (P)RR expressed in cultured vascular smooth muscle cells. These reports demonstrate that the binding affinity of prorenin to (P)RR is considerably higher than that of renin.

Soluble (P) RR: an N-terminus truncated form of full-length (P) RR

Thus far, research has been focused on the functions of the full-length $(\mathrm{P}) \mathrm{RR}$ transmembrane protein owing to its potential role in cardiovascular and renal diseases (Nguyen and Danser, 2008). Earlier, (P)RR had been described as an integral membrane protein with a size of $39 \mathrm{kDa}$ (Nguyen et al., 2002). In addition, a truncated form weighing $8.9 \mathrm{kDa}$, called M8.9, has been reported to co-precipitate with the membrane sector of the vacuolar $\mathrm{H}^{+}$ATPase (V-ATPase) obtained from bovine chromaffin granules (Ludwig et al., 1998). As there is only one gene coding for both (P)RR and M8.9 (Cousin et al., 2009), it was assumed that M8.9 must derive from the full-length (P)RR through intracellular cleavage. This was suggested to take place at a furin-like cleavage site (Burckle and Bader, 2006; Bader, 2007), which was predicted through the search for a conserved pattern in the linear aminoacid sequence of $(P) R R$. Soluble $(P) R R$ [s(P)RR] is generated intracellularly by furin cleavage, and is capable of binding renin (Cousin et al., 2009). This study also found that (P)RR was detected mainly in the Golgi apparatus, and that cleavage probably occurred in the trans-Golgi to generate a soluble form. In contrast, Yoshikawa et al. (2011) have suggested that the prorenin receptor is cleaved by A Disintegrin And Metalloproteinase 19 (ADAM19) in the Golgi complex, leading to its secretion into extracellular space. Our present study demonstrated that $\mathrm{s}(\mathrm{P}) \mathrm{RR}$ is secreted in the culture medium of human umbilical vein endothelial cells (HUVEC); the secreted amount was assessed quantitatively through an enzyme-linked immunosorbant assay (ELISA) method specifically designed for measurement of (P)RR (Biswas et al., 2011). Our study has also shown that recombinant human prorenin binds to $\mathrm{s}(\mathrm{P}) \mathrm{RR}$, and that prorenin shows renin activity as a result of interaction with this receptor (Biswas et al., 2011). Maruyama et al. (2013) have established a novel sandwich ELISA for detection of $s(P) R R$ in plasma. Recently, the pathophysiological involvement of $\mathrm{s}(\mathrm{P}) \mathrm{RR}$ has been identified in several studies. $\mathrm{s}(\mathrm{P})$ RR levels are higher in women with gestational diabetes mellitus (GDM), and that increased s(P)RR concentrations during the first trimester may be a prediction for the development of GDM during the later stages of pregnancy (Gokulakrishnan et al., 2014; Watanabe et al., 2013a). High levels of s(P)RR are also associated with likelihood of a lower SGA (small for gestational age) birth (Watanabe et al., 2013b). Further, high circulating levels of s(P)RR during the early stages of pregnancy help predict an elevated blood pressure. High concentrations of $\mathrm{s}(\mathrm{P}) \mathrm{RR}$ during delivery 
was found to be associated with preeclampsia (Watanabe et al., 2012). Although these clinical studies suggest the significance of $\mathrm{s}(\mathrm{P}) \mathrm{RR}$ during pregnancy, the detailed biochemical properties, as well as the physiological role and pathological involvement of $\mathrm{s}(\mathrm{P}) \mathrm{RR}$ in other complications, remain to be explained.

\section{Pathophysiological aspects of (P)RR}

In vitro and in vivo studies have shown that increased receptor expression could be linked to high blood pressure (Burckle and Bader, 2006). Cardiac and glomerular fibrosis is also affected by the activation of mitogen-activated protein kinases, and by upregulation of the gene expression of profibrotic molecules (Ichihara et al., 2006b; Ichihara et al., 2006c; Ichihara et al., 2008). Animal studies with angiotensin-II type 1a receptor deficiency have shown that (P)RR is also involved in the development and progression of diabetic nephropathy through angiotensin-II independent pathway, by the activation of intracellular pathways (Ichihara et al., 2008). Further, prorenin and (P)RR were found to be associated with retinal neovascularization in an experimental retinopathy model for prematurity (Satofuka et al., 2007). The same model has been used to demonstrate the involvement of prorenin and (P)RR in pathological angiogenesis, leukocyte accumulation, the interaction between intracellular adhesion molecule-1 and vascular endothelial growth factor, and retinal gene and protein expression of inflammatory mediators (Satofuka et al. 2007). Activation of tissue prorenin by $(\mathrm{P}) \mathrm{RR}$ may be involved in the pathogenesis of end-stage organ damage in hypertension and heart failure. (P)RR seems to be important for brain development and cognition as (P)RR mutation is associated with X-linked mental retardation and epilepsy (Ramser et al., 2005). Another major finding by Contrepas et al. (2009) states the role of (P)RR in neuronal cell differentiation. Recently, (P)RR has been reported to be involved in RA system-independent functions, such as correct Wnt signal activation, in Drosophila and Xenopus spp. (Cruciat et al., 2010; Buechling et al., 2010; Hermle et $a l ., 2010)$. These data explain the pathophysiological involvement of (P)RR, possibly related to the local RA system.

\section{RA system-independent effect of (P)RR}

(P)RR was initially characterized as an important component exclusive to the RA system. Recently however, its multifunctional role, such as its involvement in the regulation of intracellular and extracellular $\mathrm{pH}$ through V-ATPase-interaction, as well as in the Wnt signaling pathway, have been clearly elucidated (Figure 1). Three Wnt signaling pathways are known: the canonical Wnt/beta catenin pathway that regulates gene transcription, the non-canonical planar cell polarity (PCP) pathway that regulates the cytoskeleton responsible for the shape of cell, and the non-canonical Wnt/ calcium pathway that regulates intracellular calcium (Cruciat et al., 2010; Buechling et al., 2010; Hermle et al., 2010). All the three pathways are activated by the binding of a Wnt protein ligand to a frizzled family receptor. This receptor is associated with a coreceptor, such as lipoprotein receptor-related protein (LRP)-5/6, which passes the signal inside the cell through a Dishevelled protein. The involvement of many other proteins inside the cells, the presence of more than 20 isoforms of Wnt ligand, as well as their binding ability with different receptors and co-receptors on the cell membrane, lend to the complexity of the Wnt signaling pathway.

Cruciat et al. (2010) have shown the unexpected involvement of (P)RR in both canonical (Wnt/ $\beta$-catenin) and non-canonical (Wnt/ $\mathrm{PCP})$ signaling pathways, which are required for stem cell biology, embryonic development such as axis formation and patterning of the central nervous system, and for human diseases such as cancer. In the Wnt/beta catenin pathway, (P)RR functions in a RA systemindependent manner, as an adaptor between Wnt receptors and V-ATPase. Upon Wnt stimulation, this complex is internalized in vesicles where a proton gradient is formed by the V-ATPase, which leads to the phosphorylation of LRP-5/6 and subsequent Wnt signal transduction (Cruciat et al., 2010; Hermle et al., 2010; Buechling et al., 2010). Hermle et al. (2010) have demonstrated that the (P)RR homolog is capable of binding to frizzled receptors in both the Wnt/beta catenin and Wnt PCP pathways. In the PCP pathway, the mechanism of action of (P)RR is not very well understood. It is likely that the entire complex, comprising of Wnt bound to frizzled receptors and co-receptors, is co-internalized. It is also hypothesized that direct interaction of frizzled receptor with (P)RR is required for linking of the Wnt receptor complex to V-ATPase, and for the subsequent vesicle acidification, which is essential for vesicle traffic and Wnt signaling (Hermle et al., 2010).

The Wnt signaling pathway plays an important role in skin biology. Mammalian skin consists of a multi-layered epithelium, the interfollicular epidermis (IFE), with associated appendages such as hair follicles (HFs) and sebaceous glands (SGs), and the underlying connective tissue, the dermis. The canonical Wnt/ $\beta$-catenin signaling is crucial for HF morphogenesis, for bulge stem cell (SC) activation during hair renewal, and for directing lineage fate decisions within the epidermis (Blanpain and Fuchs, 2006; Blanpain et al., 2007; Niemann, 2006; Petersson et al., 2011). This pathway is also implicated in wound repair and cancer (Blanpain and Fuchs, 2006). The Wnt/PCP pathway is involved in HF orientation, differentiation, and cycling, as well as in wound healing (Chen and Chuong, 2011; Dworkin et al., 2011). (P)RR has recently been reported to be strongly expressed in the skin. (P)RR expression appears to be specific to the basal keratinocytes of the IFE, the outer root sheath (ORS) in the HF, and the bulge, a site where multipotent stem cells reside (Raymond et al., 2013). This RA system-independent activity of (P)RR explains the possible 
Please cite this articles as:

Biswas et al, Reviews in Agricultural Science, 2: 37-47, 2014.

doi: $10.7831 /$ ras. 2.37

reason behind its ubiquitous expression in the body.

\section{Inhibition of RA system}

Inhibition of RA system was introduced with the development of ACE inhibitors (ACEI) in the 1970s and 1980s (Rubin et al., 1978). The ACE inhibitors inhibit the conversion of angiotensin I into angiotensin II. During the 1990s, angiotensin II receptor blockers (ARBs), which are specific for the $\mathrm{AT}_{1}$ receptor, were introduced (Brunner et al., 1992; Christen et al., 1991). Both classes of drugs are now widely used in the treatment of hypertension, heart failure, and diabetic nephropathy. However, the presence of ACEIs and ARBs leads to an increase in plasma renin concentration and activity, limiting a complete inhibition of the RAS system (Azizi and Menard, 2004; Mooser et al., 1990). Moreover, ACE inhibition causes an increase in angiotensin I, which is then available for conversion to angiotensin II by ACE-independent pathways not blocked by ACEIs, such as the cathepsin- and tonin-dependent pathways (Hollenberg et al., 1998; Wolny et al., 1997). Hence, the inhibition of the RA system was proposed to be caused by a direct renin inhibitor, as this enzyme catalyzes the rate-limiting step of this system. The latest advance in this filed is the discovery of the (P)RR blocker, which was designed based on the primary structure of prorenin described by Suzuki et al. (2003). (P)RR blockers may play an effective role either as a single molecule, or synergistically with other blockers, to reduce and maintain the blood pressure at the normal level.

\section{(P)RR blockers}

Suzuki et al. (2003) proposed the presence of a short, pentameric sequence near the $\mathrm{N}$-terminal region of the prorenin prosegment. This was named as "handle" region peptide $\left(\mathrm{I}^{11 \mathrm{P}} \mathrm{FLKR}^{15 \mathrm{P}}\right.$; denoted as HRP), and was observed to protrude out of the surface of prorenin molecule, and readily bind to specific antibodies. This study demonstrated that the association of the "handle" region and the dissociation of the "gate" region $\left(\mathrm{T}^{\mathrm{TP}} \mathrm{FKR}^{10 \mathrm{P}}\right)$ play an important role in the non-proteolytic activation of prorenin by binding to (P)RR (Suzuki et al., 2003). Using this basic concept, Ichihara et al. (2004) designed a peptide consisting of 10 amino acid residues, containing a "handle" sequence called the decoy peptide $\left(\mathrm{R}^{11 \mathrm{P}}\right.$ IFLKRMPSI $\left.^{19 \mathrm{P}}\right)$. Through a substantial number of in vivo studies, they demonstrated that this peptide inhibits the binding of renin and prorenin to the receptor, and blocks their receptor-mediated signal transduction (Ichihara et al., 2004; Ichihara et al., 2006a,c; Satofuka et al., 2006). The complete inhibition of diabetic nephropathy by administering this peptide in streptozotocin-induced diabetic rats was also demonstrated (Ichihara et al., 2004). Takahashi et al. (2007), later used the same peptide to confirm the regression of established diabetic nephropathy in heminephrectomized, streptozotocin-induced diabetic rats. This peptide was also used in the attenuation of the development and progression of proteinuria and glomerulosclerosis, and reduction of renal angiotensin levels in stroke-prone, spontaneously hypertensive rats, without any observable effect on the blood pressure (Ichihara et al., 2006a). Another use of this peptide was in the attenuation of cardiac fibrosis in spontaneously hypertensive rats, fed on a highsalt diet (Ichihara et al., 2006c). Rat HRP also reduces the action potential frequency in rat brains (Shan et al., 2008). HRP inhibits the development of retinal neovascularization by interrupting the nonproteolytic activation of prorenin in the experimental retinopathy model of prematurity (Yokota et al., 2005). Satofuka et al. (2006 and 2007), using the same model, demonstrated that HRP suppresses pathological angiogenesis, leukocyte accumulation, and promotes the interaction between intracellular adhesion molecule-1 and vascular endothelial growth factor, and also reduces retinal gene and protein expression of inflammatory mediators. Kaneshiro et al. (2007) have reported the effect of human HRP on the prevention of proteinuria and glomerulosclerosis in human (P)RR transgenic rats. Susic et al. (2008) have demonstrated the blockade of prorenin activation using a decoy peptide in spontaneously hypertensive rats, on a high-salt diet. This was accompanied by a reduction in creatinine level, decreased left ventricular mass, and fibrosis. The left ventricular function was improved by treating these rats with the decoy. He et al. (2009) have demonstrated that rat HRP not only inhibits the (P)RR-attenuated mesangial cell proliferation, but also reduces the release of associated fibrotic factors like type IV collagen, phosphorylation of extracellular signal-regulated kinases 1 and 2 (ERK1/2), and the mRNA level of transforming growth factor- $\beta 1$ (TGF- $\beta 1$ ).

Using COS-7 cells, Nurun et al. (2007) have demonstrated that the decoy peptide and HRP from both rat and human, individually inhibit the binding of rat and human prorenin to their respective (P)RR on the cell membrane, with a $K$ i of $6.6 \mathrm{nM}$. Further in vitro studies have shown that, in addition to binding directly to the recombinant $(\mathrm{P}) \mathrm{RR}$, the decoy peptide competitively inhibits the binding of renin and prorenin to (P)RR (Nabi et al., 2009a; Nabi et al., 2009b). However, the reason of inhibition of renin binding to (P)RR by decoy peptide remains to be elucidated, as it is lacking in the prosegment sequence. This could be because a local conformational change might occur in the threedimensional structure of (P)RR when the decoy peptide binds to the receptor, which hinders the receptor binding to renin (Nabi and Suzuki, 2010). Furthermore, prorenin has a higher binding affinity for (P)RR than does mature renin, and the decoy sequence of the prosegment has been suggested to play an essential role in prorenin binding (Nabi et al., 2009a). The binding of decoy with high affinity to (P)RR explains the probable reason for high affinity binding of prorenin. Based on the tertiary structure of renin and the predicted tertiary structure of prorenin, it has been 
hypothesized that both renin and prorenin shared a common site other than the decoy peptide sequence, through which these molecules can interact with the (P)RR. A new sequence $\left(\mathrm{S}^{149} \mathrm{QGVLKEDVF}{ }^{158}\right)$ localized in the flexible junctional region between the $\mathrm{N}$ - and $\mathrm{C}$-domains of renin/prorenin, termed the "hinge," has recently been reported to have a pivotal role in renin/prorenin binding to (P)RR (Nabi et al., 2009a). The $K_{\mathrm{D}}$ for the binding of the "hinge" peptide to (P)RR was five times higher than that for the decoy, and was estimated to be $17.0 \mathrm{nM}$. Like the decoy, the "hinge" peptide also reduces the resonance signal of renin/prorenin binding to $(\mathrm{P}) \mathrm{RR}$ in the BIAcore sensogram. Equilibrium state analysis reveals this paradigm as a competitive inhibition with a $K_{\mathrm{i}}$ of 37.1 and $30.7 \mathrm{nM}$ for renin and prorenin binding, respectively (Nabi et al., 2009a). Therefore, this data indicates that the decoy and "hinge" region peptides together account for the higher binding affinity of prorenin. Therefore, the prorenin molecule has at least two sites, whereas renin has a single site through which these molecules can interact with the (P)RR (Nabi et al., 2009a). In contrast, it has been demonstrated that the decoy and "hinge" peptides do not inhibit the activity of the free and receptor-bound forms of mature renin, as well as the receptor-bound form of prorenin (Nabi et al., 2009a).

However, contradictory reports suggest that HRP or the decoy peptide affects neither the binding of prorenin to (P)RR, expressed on the vascular smooth muscle cells, nor Ang I generation (Batenburg et al., 2007). Some studies have also suggested that these peptides cannot block the renin- and prorenin-induced ERK 1/2 activation through (P)RR in monocytes (Feldt et al., 2008). The peptides demonstrate no effect on hypertensive nephrosclerosis in Goldblatt rats (Muller et al., 2008), and HRP shows no effects on prorenin transgenic mice (Mercure et al., 2009). The major differences regarding the HRP/decoy hypothesis, in the context of clinical studies, are yet to be explained. A probable explanation could be the differences in the experimental approach used, the peptide doses used, and the physiological conditions of the experimental model animals and/or their species (Nabi and Suzuki, 2010). Inhibition of the classical RA system and the receptor associated renin/prorenin system is shown in Figure 2.

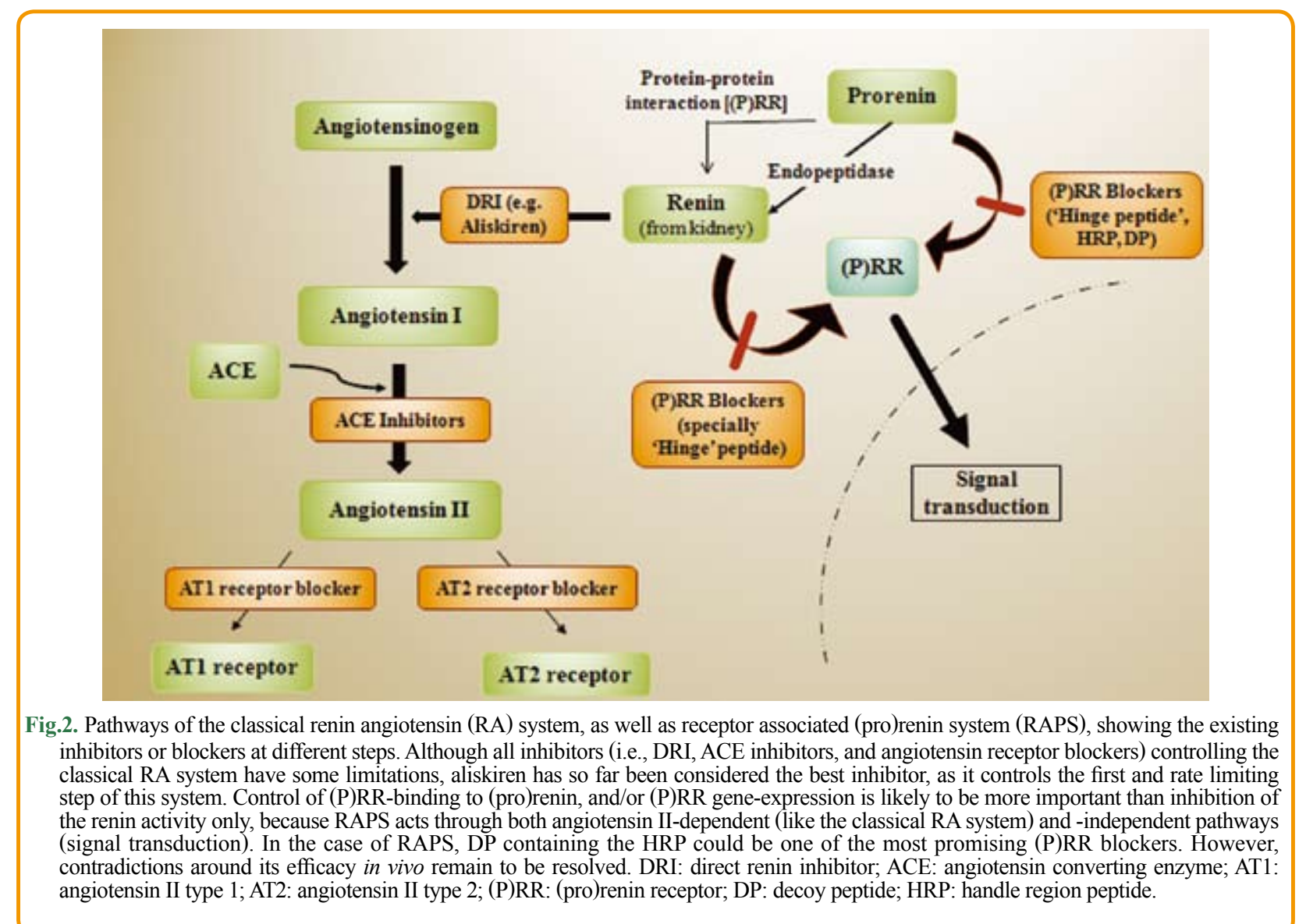


Please cite this articles as:

Biswas et al, Reviews in Agricultural Science, 2: 37-47, 2014.

doi: $10.7831 /$ ras. 2.37

Role of Aliskiren in RA system

Several peptide-like renin inhibitors have been previously synthesized, but owing to poor pharmacokinetic properties, these compounds have not been clinically utilized. For improved pharmacokinetic properties, a combination of molecular modeling and crystallographic structure analysis was employed to design renin inhibitors lacking the extended peptide-like backbone of earlier inhibitors (Wood et al., 2003). This led to the discovery of aliskiren, a highly potent and selective inhibitor of human renin in vitro and in vivo (Wood et al., 2003). Aliskiren (Tekturna; Speedel/ Novartis) is an octanamide, the first known representative of a new class of non-peptide, orally active renin inhibitors, that blocks the RA system at its rate-limiting step, and induces a net reduction in plasma renin activity, and angiotensin II and aldosterone levels (Jeunemaitre et al., 1989; Rahuel et al., 2000; Gradman et al., 2005). It binds to the active site of renin, inhibiting the entry of angiotensinogen, the only known substrate of renin.

Aliskiren is assumed to act directly on the renin-secreting juxtaglomerular cells to influence prorenin processing and renin release (Campbell, 2008), as the kidney is an important site of renin inhibitor uptake, and as aliskiren has been found in the renal glomeruli, renal arteries and capillaries (Richter et al., 1996). Aliskiren has been reported to normalize blood pressure and coronary resistance, and prevent cardiac hypertrophy and albuminuria in double transgenic rats (Mervaala et al., 2000). The renoprotective effects of aliskiren are, at least in part, due to improved renal hemodynamics and distal tubular function (Mervaala et al., 2000). Kelly et al. (2007) have shown that aliskiren reduces albuminuria and glomerulosclerosis in diabetic transgenic mice. Krop et al. (2008) have proposed that aliskiren binds intracellularly with stored renin in the secretory granules, thereby inhibiting its enzymatic activity prior to secretion. They have also shown that aliskiren is capable of binding to plasma prorenin (Krop et al., 2008). Batenburg et al. (2008) have shown that binding of aliskiren increases the plasma half-life of renin and prorenin in rat aortic vascular smooth muscle cells, and that it does not affect renin and prorenin binding to the receptors. Our study suggests that aliskiren inhibits the activity of both the free and receptor-bound forms of mature renin, and activated prorenin (Biswas et al., 2010). Moreover, when renin and aliskiren are mixed together and allowed to bind to $(\mathrm{P}) \mathrm{RR}$, renin is shown to hardly bind to the (P)RR, suggesting that aliskiren strongly inhibits the binding of renin to its receptor (Biswas et al., 2010). It could be hypothesized that aliskiren changed the local conformation of renin through binding to the active site, which is situated just upon the "hinge" region. Since renin binds to (P)RR through the "hinge" region only (Nabi et al., 2009a), the loss of flexibility of the "hinge" region due to the binding of aliskiren to the active cleft may reduce the binding affinity of renin to $(\mathrm{P}) \mathrm{RR}$ (Biswas et al., 2010). Of note is the observation that aliskiren does not inhibit renin and prorenin-induced ERK 1/2 phosphorylation and kinase activity in monocytes (Feldt et al., 2008).

Interestingly, aliskiren has been reported to reduce (P)RR gene expression in the glomeruli, tubules, and cortical vessels in streptozotocin-induced diabetic rats (Feldman et al., 2008), Moreover, aliskiren treatment is associated with a significant decrease in $(\mathrm{P}) \mathrm{RR}$ expression in the kidney cortex of diabetic hypertensive Ren2 rats (Nguyen and Contrepas, 2008). A recent study has also revealed that aliskiren reduces $(P) R R$ expression and activity in cultured human aortic smooth muscle cells (HSMCs) (Ferri et al., 2011). Co-incubation of HSMCs with human recombinant prorenin and aliskiren results in a concentration-dependent reduction of (P)RR mRNA levels. The cell surface expression of (P)RR, determined by flow cytometry, was also observed to reduce in a dose-dependent manner. The lower levels of $(\mathrm{P}) \mathrm{RR}$ are associated with a reduced expression of transforming growth factor (TGF)- $\beta$, plasminogen activator inhibitor (PAI)-I, and type I collagen mRNA (Ferri et al., 2011).

\section{Concluding remarks}

Despite extensive research efforts and the significant advances achieved through a substantial number of in vivo and in vitro studies toward the understanding of renin, prorenin, and (P)RR, several important issues are yet to be elucidated. Our main concern now is to control (P)RR activity and/or expression. The existing (P)RR blocker could be one of the solutions (Nabi et al., 2012) for this; however, the contradictions regarding the use of HRP must be addressed first, focusing on its efficacy and doses. Before such concerns are addressed, it is important to confirm the efficacy of HRP in the suppression of (P)RR gene expression, as studies have demonstrated that aliskiren does not affect (P)RR mRNA levels in the human mesangial cells (Feldman et al., 2008). The protein (P)RR levels may also be determined using customized ELISA techniques for the measurement of $\mathrm{s}(\mathrm{P}) \mathrm{RR}$ concentration in both cultured medium and human plasma. Determination of the three dimensional structure of $(\mathrm{P}) \mathrm{RR}$ is now indeed the highest priority regarding RA research, in order to facilitate the better understanding of the suitability of existing inhibitors, as well as to discover promising new ones. In some cases, such as the skin and hair cells, stimulation rather than inhibition of (P)RR may potentially be required for the induction of Wnt signaling pathway.

\section{References}

Azizi M and Menard J (2004) Combined blockade of the reninangiotensin system with angiotensin-converting enzyme inhibitors and angiotensin II type 1 receptor antagonists. 
Circulation, 109: 2492-2499.

Bader M (2007) The second life of the (pro)renin receptor. J. Renin Angiotensin Aldosterone Syst., 8: 205-208.

Batenburg WW, Krop M, Garrelds IM, de Vries R, de Bruin RJA, Burcklé CA, Müller DN, Bader M, Nguyen G and Danser AHJ (2007) Prorenin is the endogenous agonist of the (pro)renin receptor. Binding kinetics of renin and prorenin in rat vascular smooth muscle cells overexpressing the human (pro)renin receptor. J. Hypertens., 25: 2441-2453.

Batenburg WW, de Bruin RJA, van Gool JMG, Muller DN, Bader M, Nguyen G and Danser AHJ (2008) Aliskiren-binding increases the half-life of renin and prorenin in rat aortic vascular smooth muscle cells. Arterioscler. Thromb. Vasc. Biol., 28: 1151-1157.

Biswas KB, Nabi AHMN, Arai Y, Nakagawa T, Ebihara A, Ichihara I, Watanabe T, Inagami T and Suzuki F (2010) Aliskiren binds to renin and prorenin bound to (pro)renin receptor in vitro. Hypertens. Res., 33: 1053-1059.

Biswas KB, Nabi AN, Arai Y, Nakagawa T, Ebihara A, Inagami $\mathrm{T}$ and Suzuki F (2011) Qualitative and quantitative analyses of (pro)renin receptor in the medium of cultured human umbilical vein endothelial cells. Hypertens. Res., 34: 735-739.

Blanpain C and Fuchs E (2006) Epidermal stem cells of the skin. Annu. Rev. Dev. Biol., 22: 339-373.

Blanpain C, Horsley V and Fuchs E (2007) Epithelial stem cells: turning over new leaves. Cell, 128: 445-458.

Brunner HR, Christen Y, Munafo A, Lee RJ, Waeber B and Nussberger J (1992) Clinical experience with angiotensin II receptor antagonists. Am. J. Hypertens., 5: 243S-246S.

Buechling T, Bartscherer K, Ohkawara B, Chaudhary V, Spirohn K, Niehrs $C$ and Boutros $M$ (2010) Wnt/Frizzled signaling requires dPRR, the Drosophila homolog of the prorenin receptor. Curr. Biol., 20: 1263-1268.

Burckle C and Bader M (2006) Prorenin and its ancient receptor. Hypertension, 48: 549-551.

Campbell DJ (2008) Interpretation of plasma renin concentration in patients receiving aliskiren therapy. Hypertension, 51:15-18.

Chen J and Chuong CM (2011) Patterning skin by planar cell polarity: the multi-talented hair designer. Exp. Dermatol., 21: 81-85.

Christen Y, Waeber B, Nussberger J, Porchet M, Borland RM, Lee RJ, Maggon K, Shum L, Timmermans PB and Brunner HR (1991) Oral administration of DuP 753, a specific angiotensin II receptor antagonist, to normal male volunteers. Inhibition of pressor response to exogenous angiotensin I and II. Circulation, 83: 1333-1342.

Contrepas A, Walker J, Koulakoff A, Franek KJ, Qadri F, Giaume, Corvol P, Schwartz CE and Nguyen G (2009) A role of the (pro)renin receptor in neuronal cell differentiation. Am. J. Physiol. Regul. Comp. Physiol., 297: R250-R257.
Cousin C, Bracquart D, Contrepas A, Corvol P, Muller L and Nguyen G (2009) Soluble form of the (pro)renin receptor generated by intracellular cleavage by furin is secreted in plasma. Hypertension, 53: 1077-1082.

Cruciat CM, Ohkawara B, Acebron SP, Karaulanov E, Reinhard C, Ingelfinger D, Boutros M and Niehrs C (2010) Requirement of (pro)renin receptor and vacuolar $\mathrm{H}^{+}$-ATPase-mediated acidification for Wnt signaling. Science, 327: 459-463.

Danser AHJ and Deinum J (2005) Renin, prorenin and the putative (pro)renin receptor. Hypertension, 46: 1069-1076.

Danser AHJ, Batenburg WW, van Esch JHM and Krop M (2008) Prorenin anno 2008. J. Mol. Med., 86: 655-658.

Demirci FY, White NJ, Rigatti BW, Lewis KF and Gorin MB (2001) Identification, genomic structure, and screening of the vacuolar proton-ATPase membrane sector-associated protein M8-9 gene within the COD1 critical region (Xp11.4). Mol. Vision., 7: 234-239.

Dworkin S, Jane SM and Darido C (2011) Planar cell polarity pathway in vertebrate epidermal development, homeostasis and repair. Organogenesis, 7: 202-208.

Feldman DL, Jin L, Xuan H, Contrepas A, Zhou Y, Webb RL, Muller DN, Feldt S, Cumin F, Maniara W, Persohn E, Schuetz H, Danser AHJ and Nguyen G (2008) Effects of aliskiren on blood pressure, albuminuria, and (pro)renin receptor expression in diabetic TG(mRen-2)27 rats. Hypertension, 52: 130-136.

Feldt, S, Batenburg WW, Mazak I, Maschke U, Wellner M, Kvakan H, Dechend R, Fiebeler A, Burckle C, Contrepas A, Danser AHJ, Bader M, Nguyen G, Luft FC and Muller DN (2008) Prorenin and renin-induced extracellular signal-regulated kinase $1 / 2$ activation in monocytes is not blocked by aliskiren or the handle-region peptide. Hypertension 2008; 51: 682-688.

Ferri N, Greco CM, Maiocchi G and Corsini A (2011) Aliskiren reduces prorenin receptor expression and activity in cultured human aortic smooth muscle cells. J. Renin Angiotensin Aldosterone Syst., 12: 469-474.

Gokulakrishnan K, Maheswari K, Mahalakshmi MM, Kalaiyarasi G, Bhavadharini B, Pandey GK, Ramesh J, Ram U and Mohan V (2014) Association of soluble (PRO) renin receptor with gestatinal diabetes receptor. Endocr. Pract., 6: 1-26.

Goto M, Mukoyama M, Suga SI, Matsumoto T, Nakagawa M, Ishibashi R, Kasahara M, Sugawara A, Tanaka I and Nakao K (1997) Growth-dependent induction of angiotensin II type 2 receptor in rat mesangial cells. Hypertension, 30: 358-362.

Gradman A, Schmieder RE, Lins RL, Nussberger J, Chiang Y and Bedigian MP (2005) Aliskiren, a novel orally effective renin inhibitor, provides dose-dependent antihypertensive efficacy and placebo-like tolerability in hypertensive patients. Circulation, 111: 1012-1018.

Gross V, Schunck WH, Honeck H, Milia AF, Kärgel E, Walther 
Please cite this articles as:

Biswas et al, Reviews in Agricultural Science, 2: 37-47, 2014.

doi: $10.7831 /$ ras. 2.37

T, Bader M, Inagami T, Schneider W and Luft FC (2000) Inhibition of pressure natriuresis in mice lacking the AT receptor. Kidney Int., 57: 191-202.

He M, Zhang L, Shao Y, Wang X, Huang Y, Yao T and Lu L (2009) Inhibition of renin/prorenin receptor attenuated mesangial cell proliferation and reduced associated fibrotic factor release. Eur. J. Pharmacol., 606: 155-161.

Hermle T, Saltukoglu D, Grunewald J, Walz G and Simons M (2010) Regulation of Frizzled-dependent planar polarity signaling by a V-ATPase subunit. Curr. Biol., 20: 1269-1276.

Hollenberg NK, Fisher ND and Price DA (1998) Pathways for angiotensin II generation in intact human tissue: evidence from comparative pharmacological interruption of the renin system. Hypertension, 32: 387-392.

Huang Y, Wongamorntham S, Kasting J, McQuillan D, Owens RT, Yu L, Noble NA and Border W (2006) Renin increases mesangial cell transforming growth factor-beta1 and matrix proteins through receptor-mediated, angiotensin II-independent mechanisms. Kidney Int., 69: 105-113.

Ichihara A, Hayashi M, Kaneshiro Y, Suzuki F, Nakagawa T, Tada Y, Koura Y, Nishiyama A, Okada H, Uddin MN, Nabi AH, Ishida Y, Inagami T and Saruta T (2004) Inhibition of diabetic nephropathy by a decoy peptide corresponding to the "handle" region for nonproteolytic activation of prorenin. J. Clin. Invest., 114: 1128-1135.

Ichihara A, Kaneshiro Y, Takemitsu T, Sakoda M, Nakagawa T, Nishiyama A, Kawachi H, Shimizu F and Inagami T (2006a) Contribution of non-proteolytically activated prorenin in glomeruli to hypertensive renal damage. J. Am. Soc. Nephrol., 17: 2495-2503.

Ichihara A, Kaneshiro Y, Takemitsu T, Sakoda M, Suzuki F, Nakagawa T, Nishiyama A, Inagami T and Hayashi M (2006b) Nonproteolytic activation of prorenin contributes to development of cardiac fibrosis in genetic hypertension. Hypertension, 47: 894-900.

Ichihara A, Sakoda M, Kurauchi-Mito A, Kaneshiro Y and Itoh $H$ (2008) Involvement of (pro)renin receptor in the glomerular filtration barrier. J. Mol. Med., 86: 629-635.

Ichihara A, Suzuki F, Nakagawa T, Kaneshiro Y, Takemitsu T, Sakoda M, Nabi AH, Nishiyama A, Sugaya T, Hayashi M and Inagami T (2006c) Prorenin receptor blockade inhibits development of glomerulosclerosis in diabetic angiotensin II type 1a receptor-deficient mice. J. Am. Soc. Nephrol., 17: 1950-1961.

Ito M, Oliverio I, Mannon PJ, Best CF, Maeda N, Smithies O and Coffman TM (1995) Regulation of blood pressure by the type $1 \mathrm{~A}$ angiotensin II receptor gene. Proc. Natl. Acad. Sci. USA, 92: 3521-3525.

Jeunemaitre X, Menard J, Nussberger J, Guyene TT, Brunner HR and Corvol P (1989) Plasma angiotensins, renin, and blood pressure during acute renin inhibition by CGP $38560 \mathrm{~A}$ in hypertensive patients. Am. J. Hypertens., 2: 819-827.

Kaneshiro Y, Ichihara A, Sakoda M, Takemitsu T, Nabi AH, Uddin MN, Nakagawa T, Nishiyama A, Suzuki F, Inagami T and Itoh H (2007) Slowly progressive, angiotensin II-independent glomerulosclerosis in human (pro)renin receptor-transgenic rats. J. Am. Soc. Nephrol., 18: 1789-1795.

Kaneshiro Y, Ichihara A, Takemitsu T, Sakoda M, Suzuki F, Nakagawa T, Hayashi $M$ and Inagami $T$ (2006) Increased expression of cyclooxygenase- 2 in the renal cortex of human prorenin receptor gene-transgenic rats. Kidney Int., 70: 641-646.

Kelly DJ, Zhang Y, Moe G, Naik G and Gilbert RE (2007) Aliskiren, a novel renin inhibitor, is renoprotective in a model of advanced diabetic nephropathy in rats. Diabetologia, 50: 2398-2404.

Krebs C, Hamming I, Sadaghiani S, Steinmetz OM, MeyerSchwesinger C, Fehr S, Stahl RA, Garrelds IM, Danser AH, van Goor H, Contrepas A, Nguyen G and Wenzel U (2007) Antihypertensive therapy upregulates renin and (pro)renin receptor in the clipped kidney of Goldblatt hypertensive rats. Kidney Int., 72: 725-730.

Krop M, Garrelds IM, de Bruin RJA, van Gool JMG, Fisher NDL, Hollenberg NK and Danser AHJ (2008) Aliskiren accumulates in renin secretory granules and binds plasma prorenin. Hypertension, 52: 1076-1083.

Leckie BJ, Birnie G and Carachi R (1994) Renin in Wilms' tumor: prorenin as an indicator. J. Clin. Endocrinol. Metab., 79: 1742-1746.

Ludwig J, Kerscher S, Brandt U, Pfeiffer K, Getlawi F, Apps DK and Schagger H (1998) Identification and characterization of a novel 9.2-kDa membrane sector-associated protein of vacuolar proton-ATPase from chromaffin granules. J. Biol. Chem., 273: 10939-10947.

Luetscher JA, Kraemer FB, Wilson DM, Schwartz HC and BryerAsh M (1985) Increased plasma inactive renin in diabetes mellitus. A marker of microvascular complications. N. Engl. J. Med., 312: 1412-1417.

Maruyama N, Segawa T, Kinoshita N and Ichihara A (2013) Novel sandwich ELISA for detecting the human soluble (pro)renin receptor. Front. Biosci., 5: 583-590.

Mercure C, Prescott G, Lacombe MJ, Silversides DW and Reudelhuber TL (2009) Chronic increases in circulating prorenin are not associated with renal or cardiac pathologies. Hypertension, 53: 1062-1069.

Mervaala E, Müller DN, Schmidt F, Park JK, Gross V, Bader M, Breu V, Ganten D, Haller H and Luft FC (2000) Blood pressureindependent effects in rats with human renin and angiotensinogen genes. Hypertension, 35: 587-594.

Mooser V, Nussberger J and Jullierat L (1990) Reactive hyperreninemia is a major determinant of plasma angiotensin II 
during ACE inhibition. J. Cardiovasc. Pharmacol., 15: 276-282.

Muller DN, Klanke B, Feldt S, Cordasic N, Hartner A, Schmieder RE, Luft FC and Hilgers KF (2008) (Pro)renin receptor peptide inhibitor "handle-region" peptide does not affect hypertensive nephrosclerosis in Goldblatt rats. Hypertension, 51: 676-681.

Nabi AH and Suzuki F (2010) Biochemical properties of renin and prorenin binding to the (pro)renin receptor. Hypertens. Res., 33: 91-97.

Nabi AHMN, Biswas KB, Arai Y, Nakagawa T, Ebihara A, Islam LN and Suzuki F (2012) (Pro)renin receptor and prorenin: their plausible sites of interaction. Front. Biosci., 17: 389-395.

Nabi AHMN, Biswas KB, Nakagawa T, Ichihara A, Inagami T and Suzuki F (2009a) Prorenin has high affinity multiple binding sites for (pro)renin receptor. Biochim. Biophys. Acta., 1794: 1838-1847.

Nabi AHMN, Biswas KB, Nakagawa T, Ichihara A, Inagami T and Suzuki F (2009b) Decoy peptide' region (RIFLKRMPSI) of prorenin prosegment plays a crucial role in prorenin binding to the (pro)renin receptor. Int. J. Mol. Med., 24: 83-89.

Nabi AHMN, Kageshima A, Uddin MN, Nakagawa T, Park EY and Suzuki F (2006) Binding properties of rat prorenin and renin to the recombinant rat renin/prorenin receptor prepared by a baculovirus expression system. Int. J. Mol. Med., 18: 483-488.

Nelson N and Harvey WR (1999) Vacuolar and plasma membrane proton-adenosine triphosphatases. Physiol. Rev., 79: 361-385.

Nguyen G (2006) Renin/prorenin receptors. Kidney Int., 69: 1503-1506.

Nguyen G (2011) Renin and prorenin receptor in hypertension: what's new? Curr. Hypertens. Rep., 13: 79-85.

Nguyen G and Contrepas A (2008) The (pro)renin receptors. J. Mol. Med., 86: 643-646.

Nguyen G and Danser AHJ (2008) Prorenin and (pro)renin receptor: a review of available data from in vitro studies and experimental models in rodents. Exp. Physiol., 93: 557-563.

Nguyen G, Delarue F, Burcklé C, Bouzhir L, Giller T and Sraer JD (2002) Pivotal role of the renin/prorenin receptor in angiotensin II production and cellular responses to renin. J. Clin. Invest., 109: 1417-1427.

Niemann C (2006) Controlling the stem cell niche: right time, right place, right strength. Bioassays; 28: 1-5.

Nishi T and Forgac M (2002) The vacuolar $\left(\mathrm{H}^{+}\right)$-ATPases nature's most versatile proton pumps. Nat. Rev. Mol. Cell. Biol., 3: 94-103.

Nurun NA, Uddin MN, Nakagawa T, Iwata H, Ichihara A, Inagami T and Suzuki F (2007) Role of "handle" region of prorenin prosegment in the non-proteolytic activation of prorenin by binding to membrane anchored (pro)renin receptor. Front. Biosci., 12: 4810-4817.

Petersson M, Brylka H, Kraus A, John S, Rappl G, Schettina P and
Niemann C (2011) TCF/LEF1 activity controls establishment of diverse stem and progenitor cell compartments in mouse epidermis. EMBO J., 30: 3004-3018.

Rahuel J, Rasetti V, Maibaum J, Rueger H, Goschke R, Cohen NC, Stutz S, Cumin F, Fuhrer W, Wood JM and Grutter MG (2000) Structure-based drug design: the discovery of a novel nonpeptide orally active inhibitors of human renin. Chem. Biol., 7: 493-504.

Ramser J, Abidi FE, Burckle CA, Lenski C, Toriello H, Wen G, Lubs HA, Engert S, Stevenson RE, Meindl A, Schwartz CE and Nguyen $G$ (2005) A unique exonic splice enhancer mutation in a family with X-linked mental retardation and epilepsy points to a novel role of the renin receptor. Hum. Mol. Genet., 14: 1019-1027.

Raymond K, Martin S, Aractingi S and Lebrin F (2013) The (pro)renin receptor controls Wnt signaling: promise from Drosophila and Xenopus. Eur. J. Dermatol., In press.

Richter WF, Whitby BR and Chou RC (1996) Distribution of remikiren, a potent orally active inhibitor of human renin, in laboratory animals. Xenobiotica, 26: 243-254.

Rubin B, Antonaccio MJ and Horovitz ZP (1978) Captopril (SQ 14,225) (D-3-mercapto-2-methylpropranoyl-1-proline): a novel orally active inhibitor of angiotensin-converting enzyme and antihypertensive agent. Prog. Cardiovasc. Dis., 21: 183-194.

Saris JJ, 't Hoen PA, Garrelds IM, Dekkers DH, den Dunnen JT, Lamers JM and Danser AHJ (2006) Prorenin induces intracellular signalling in cardiomyocytes independently of angiotensin II. Hypertension, 48: 564-571.

Satofuka S, Ichihara A, Nagai N, Koto T, Shinoda H, Noda K, Ozawa Y, Inoue M, Tsubota K, Itoh H, Oike Y and Ishida S (2007) Role of nonproteolytically activated prorenin in pathologic, but not physiologic, retinal neovascularization. Invest. Ophthalmol. Vis. Sci., 48: 422-429.

Satofuka S, Ichihara A, Nagai N, Yamashiro K, Koto T, Shinoda H, Noda K, Ozawa Y, Inoue M, Tsubota K, Suzuki F, Oike Y and Ishida $S$ (2006) Suppression of ocular inflammation in endotoxininduced uveitis by inhibiting nonproteolytic activation of prorenin. Invest. Ophthalmol. Vis. Sci., 47: 2686-2692.

Schefe JH, Menk M, Reinemund J, Effertz K, Hobbs RM, Pandolfi PP, Ruiz P, Unger T and Funke-Kaiser H (2006) A novel signal transduction cascade involving direct physical interaction of the renin/prorenin receptor with the transcription factor promyelocytic zinc finger protein. Circ. Res., 99: 1155-1166.

Shan Z, Cuadra AE, Sumners C and Raizada MK (2008) Characterization of a functional (pro)renin receptor in rat brain neurons. Exp. Physiol., 93: 701-708.

Siragy HM and Carey RM (1997) The subtype-2 (AT) angiotensin receptor mediates renal production of nitric oxide in conscious rats. J. Clin. Invest., 100: 264-269.

Susic D, Zhou X, Frohlich ED, Lippton H and Knight M (2008) 
Please cite this articles as:

Biswas et al, Reviews in Agricultural Science, 2: 37-47, 2014.

doi: $10.7831 /$ ras.2.37

Cardiovascular effects of prorenin blockade in genetically hypertensive rats (SHR) on normal and high salt diet. Am. J. Physiol. Heart. Circ. Physiol., 295: H1117-H1121.

Suzuki F, Hayakawa M, Nakagawa T, Nasir UM, Ebihara A, Iwasawa A, Ishida Y, Nakamura Y and Murakami K (2003) Human prorenin has "gate and handle" regions for its nonproteolytic activation. J. Biol. Chem., 278: 22217-22222.

Takahashi H, Ichihara A, Kaneshiro Y, Inomata K, Sakoda M, Takemitsu T, Nishiyama A and Itoh H (2007) Regression of nephropathy developed in diabetes by (pro)renin receptor blockade. J. Am. Soc. Nephrol., 18: 2054-2061.

Tigerstedt R and Bergman PG (1898) Niere und Kreislauf. Skand. Arch. Physiol., 8: 223-271.

Watanabe N, Morimoto S, Fujiwara T, Suzuki T, Taniguchi K, Mori F, Ando T, Watanabe D, Kimura T, Sago H and Ichihara A (2013a) Prediction of gestational diabetes mellitus by soluble (pro)renin receptor during the first trimester. J. Clin. Endocrinol. Metab., 98: 2528-2535.

Watanabe N, Bokuda K, Fujiwara T, Suzuki T, Mito A, Morimoto S, Jwa SC, Egawa M, Arai Y, Suzuki F, Sago H and Ichihara A (2012) Soluble (pro)renin receptor and blood pressure during pregnancy: a prospective cohort study. Hypertension, 60: 1250-1256.

Watanabe N, Morimoto S, Fujiwara T, Suzuki T, Taniguchi K, Ando T, Kimura T, Sago H and Ichihara A (2013b) Association between soluble (pro)renin receptor concentration in cord blood and small for gestational age birth: a cross-sectional study. PLoS One, 8: e60036.

Wolny A, Clozel JP, Rein J, Mory P, Vogt P, Turino M, Kiowski W and Fischli W (1997) Functional and biochemical analysis of angiotensin II-forming pathways in the human heart. Circ. Res., 80: 219-227.

Wood JM, Maibaum J, Rahuel J, Grütter MG, Cohen NC, Rasetti V, Rüger H, Göschke R, Stutz S, Fuhrer W, Schilling W, Rigollier P, Yamaguchi Y, Cumin F, Baum HP, Schnell CR, Herold P, Mah R, Jensen C, O'Brien E, Stanton A and Bedigian MP (2003) Structure-based design of aliskiren, a novel orally effective renin inhibitor. Biochem. Biophys. Res. Commun., 308: 698-705.

Yokota H, Mori F, Kai K, Nagaoka T and Izumi N (2005) Serum prorenin levels and diabetic retinopathy in type 2 diabetes: $\mathrm{J}$ new method to measure serum level of prorenin using antibody activating direct kinetic assay. Br. J. Ophthalmol., 89: 871-873.

Yoshikawa A, Aizaki Y, Kusano K, Kishi F, Susumu T, Iida S, Ishiura S, Nishimura S, Shichiri M and Senbonmatsu T (2011) The (pro)renin receptor is cleaved by ADAM19 in the Golgi leading to its secretion onto extracellular space. Hypertens. Res., 34: 599-605.

Zhang J, Noble NA, Border WA, Owens RT and Huang Y (2008) Receptor-dependent prorenin activation and induction of PAI-1 expression in vascular smooth muscle cells. Am. J. Physiol.
Endocrinol. Metab., 295: E810-E819.

Zhang Y, Gao X and Michael Garavito R (2011) Structural analysis of the intracellular domain of (pro)renin receptor fused to maltosebinding protein. Biochem. Biophys. Res. Commun., 407: 674-679. 